\title{
Can Farm Sustainability Translate into Efficiency as Well? A Technical Efficiency Analysis of Relay Cropping System in Saurashtra, Gujarat
}

\author{
Vasavada, K.M. ${ }^{1 \text {, }}$, Dhandhalya, M.G. ${ }^{1}$, Swaminathan, B..$^{1 *}$ and Thanki, P.M. ${ }^{2}$ \\ ${ }^{1}$ Department of Agricultural Economics, Junagadh Agricultural University, Junagadh-362001, Gujarat State, India \\ ${ }^{2}$ Department of Agricultural Economics, Navsari Agricultural University, Bharuch -392012, Gujarat State, India \\ *Corresponding author: bswaminathan@jau.in
}

\begin{abstract}
Exploiting the potential of current technologies is more critical to increase farm production than that of waiting for a new technological breakthrough. In reality, higher efficiency can often translate into higher productivity which further may lead to sustainability at the farm levels. Taking this into consideration, the present study was conducted in Saurashtara region of Gujarat state during 2016-17 to determine technical efficiency levels of randomly selected farmers practicing groundnut-pigeonpea relay cropping vis-à-vis other cropping systems. The analysis was conducted using stochastic frontier production function (SFPF) approach. The findings revealed that the mean technical efficiency of relay cropping farmers (89\%) was higher than that of sole pigeonpea farmers (87.18\%) and sole groundnut farmers $(74.52 \%)$. The maximum likelihood estimates (MLE) revealed positively significant effect of human labour (1.103) and machine power (0.109) and fertilizer (0.276) on farm output among relay cropping farmers. In fact, the variance ratios viz. $\sigma^{2}(0.027), \gamma(0.838)$ and $\lambda(2.263)$ were found to be significant indicating that the variations in the farm output were more due to the existence of technical inefficiency levels. In addition, the average frontier yield to be bridged was only $0.89 \mathrm{qtl} / \mathrm{ha}$ under relay cropping which was much lesser than the other two cropping systems. Among the factors influencing the technical efficiency of relay cropping farmers, experience (0.37); education (0.10); institutional support (0.12) and imput market access (0.08) were found to be both positive and significant.
\end{abstract}

Keywords: Technical Efficiency, Determinants, Relay cropping, Gujarat

Technical efficiency of farmers in a given area can be defined as the ratio of farmer's actual output to the technically possible frontier (maximum) output in the same area using the given level of resources. It can be used as an indicator of farm productivity and the variations in technical efficiency of farmers may influence the productivity differences which in-turn can impact the sustainability of cropping systems as well. In general, a cropping system refers to a series of crop production activities leading to either diversification or specialization. If a cropping system focuses on the sustainable component (i.e. optimal use of farm inputs / scarce resources) along with the scope of generating and sustaining additional returns to the farmers, then it can be considered as a sustainable cropping system. Of late, the monocropping practices are fast becoming the norm of the day but sustainable cropping systems are still practiced in many traditional cropping areas in India, especially those which are resource or income poor. Relay cropping is one of the methods of sustainable cropping system whereby the second crop is sown well before the harvesting of the standing first crop. Such a cropping system may solve a number of conflicts including inefficient use of available resources, controversies in sowing time, optimal fertilizer application besides arresting soil degradation issues.

Among the critical issues delibrated in the current phase of agricultural sector, requirements of the 
next technological phase and efficiency parameters of the prevailing phase cannot go unconsidered. But there is no point in anticipating for the new break-through technology without exploiting the potentitality of the current technology. With ever decreasing scope for expanding land frontiers and increasing trend of diversion of cultivable lands for non-agricultural purposes (Deshpande and Bhende, 2003), the only option remaining is to increase agricultural production through improved adoption of technologies among farmers and efficient use of available resources. One such cropping system that promotes maximum utilization of resources is groundnut-pigeonpea relay cropping which is widely prevalent in the dry and arid tracts of India. Apart from the academic interest of crop rotation, nitrogen fixation and sustainability, the groundnut-pigeonpea relay cropping system needs to be encouraged among the farmers to increase the economic returns per unit area.

Saurashtra region is one such important pocket of groundnut-pigeonpea relay cropping system in India where groundnut happens to be a ruling kharif crop accounting for 86 per cent of the total groundnut production in the state. At the same time, the region experiences high variability in rainfall leading to high instability in crop production as well. Under such conditions, an alternate and more viable proposition could be to raise short duration crops.

In this manner, the practice of relay cropping system may help the farmers to reduce the risk of crop failure in mono-cropping systems. Besides, a relay cropping system may also result in optimum utilization of resources which in-turn may result in increased yield levels per unit area. And only when the yield levels are increased with lesser costs, a farmer may be motivated to continue relay cropping or any other sustainable cropping system. For ensuring higher productivity and to sustain it, the farmer's efficiency dealing with the utilization of available resources needs to be on a higher plane.

In view of the above discussions, the present study was undertaken with the specific objectives of assessing the farm level technical efficiency of groundnut-pigeonpea relay cropping system along with its determinants and comparing it vis-à-vis other mono-cropping systems in the study area.

\section{Methodological framework}

For the present study, two districts of the Saurashtra region viz. Junagadh and Jamnagar were selected purposively where the farmers follow the practice of relay cropping system for the past ten years at least. Subsequently, one taluka each from each selected district viz. Junagadh taluka (Junagadh) and Jamjodpur taluka (Jamnagar) were chosen. This was followed by the selection of two villages from each of the taluka such as Agatarai and Nanighansari (Junagadh taluka) and Amrapar and Gingani (Jamjodpurtaluka). From each village, 12 farmers practicing relay cropping system (groundnut + pigeonpea) and 12 farmers each growing sole groundnut and sole pigeonpea were selected randomly as the ultimate sampling unit. Thus, a sample size of 48 farm respondents each for relay cropping of groundnut + pigeonpea, sole groundnut and sole pigeonpea were selected resulting in to a total sample size of 144 . The primary data on acreage, yield and inputs used were collected along with the socio-economic and demographic characteristics by using a pre-tested interview schedule. The primay survey was carried out during kharif in the year 2016-17.

\section{Analytical tools}

Following Aigner et al. (1977); Sharma and Datta (1997); Taru et al. (2011) and Varsani et al. (2016), the stochastic frontier production function approach was used in the present study to measure the technical efficiency of relay cropping vis-à-vis sole crop farms i.e. groundnut and pigeonpea.

In a technical efficiency analysis, the maximum possible output that could be obtained from a given bundle of inputs and technology is important and not just the average output obtained by the farmers in a study area. Exploiting the potentiality of existing technology by improving technical efficiency among farmers is as important as the search for new technology (Bhende and Kalirajan, 2007).

\section{Stochastic Frontier Production Function}

In a stochastic frontier production function approach, an efficient farm is said to operate on the production frontier while inefficient farmes are those operating below the production frontier. The stochastic 
frontier production of Cobb-Douglas specification used in the study is of the following form:

$$
Y_{i}=f\left(X_{i} ; \beta_{i}\right) \exp \left(v_{i}-u_{i}\right) i=1,2,3, \ldots \ldots, n
$$

Where, $\mathrm{Y}_{\mathrm{i}}$ is the possible production level of the $\mathrm{i}^{\text {th }}$ firm, $\mathrm{f}\left(\mathrm{X}_{\mathrm{i}} ; \beta_{\mathrm{i}}\right)$ is the suitable functional form (i.e. Cobb-Douglas) of the vector of inputs $\left(X_{i}\right)$ and a vector of unknown parameters $\left(\beta_{i}\right) ; v_{i}$ is the randomly distributed and symmetrically two-sided error term such as $\mathrm{v} \sim \mathrm{N}\left(0, \sigma^{2} \mathrm{v}\right)$ capturing the effects of random shocks outside the farmer's control i.e. observation and measurement error, implications of natural phenomena (floods, droughts, etc.) and statistical noise; $u_{i}$ is the half-normal distributed, one sided error term such as $\mathrm{u} \sim \mathrm{N}\left(0, \sigma^{2} \mathrm{u}\right)$ capturing randomness under the control of the farmer (i.e. inefficiency). This way, both $\mathrm{v}_{\mathrm{i}}$ and $\mathrm{u}_{\mathrm{i}}$ are independent of each other and $v_{i}$ allows the frontier to vary across farms or over time for the same farm and therefore the frontier is stochastic.

Further, a measure of technical efficiency of the $i^{\text {th }}$ firm can be given by:

$$
\begin{aligned}
& \underset{\mathrm{i}}{\mathrm{TE}_{\mathrm{i}}}=\mathrm{Y}_{\mathrm{i}} / \mathrm{Y}_{\mathrm{i}} *=\text { Actual output } / \text { Maximum possible } \\
&=\mathrm{f}\left(\mathrm{X}_{\mathrm{i}} ; \beta_{\mathrm{i}}\right) \exp \left(\mathrm{v}_{\mathrm{i}}-\mathrm{u}_{\mathrm{i}}\right) / \mathrm{f}\left(\mathrm{X}_{\mathrm{i}} ; \beta_{\mathrm{i}}\right) \exp \left(\mathrm{v}_{\mathrm{i}}\right) \ldots(3) \\
&=\exp \left(-\mathrm{u}_{\mathrm{i}}\right)
\end{aligned}
$$

Following Jondrow et al. (1982), the prediction of technical efficiencies of individual farms associated with the stochastic frontier production function $Y_{i}=f$ $\left(X_{i} ; \beta_{i}\right) \exp \left(v_{i}-u_{i}\right) ; i=1,2,3, \ldots \ldots . ., n$ and defined by $\mathrm{TE}=\exp \left(-\mathrm{u}_{\mathrm{i}}\right) \mathrm{i}=1,2, \ldots \ldots, \mathrm{n}$ was estimated by,

$$
\mathrm{E}(\mathrm{u})=(\sqrt{ } 2 / \Pi) \sigma_{\mathrm{u}}
$$

Thereby, equation (5) is the formula used for estimating the average level of technical inefficiency in the study area.

The expected value of $u_{i}$ i.e. the technical inefficiency of the $i^{\text {th }}$ farm was calculated by using the distribution of $u_{i}$ conditional on the total error term i.e. $\left(v_{i}-u_{i}\right)$ which is as follows:

$$
\begin{aligned}
& \mathrm{E}\left(\mathrm{u}_{\mathrm{i}} \epsilon_{\mathrm{i}}\right)=\sigma^{*}\left[\left\{\mathrm{f}\left(\varepsilon_{\mathrm{i}} \lambda / \sigma\right) /\left(1-\mathrm{F}\left(\varepsilon_{\mathrm{i}} \lambda / \sigma\right)\right\}-\left(\mathrm{e}_{\mathrm{i}} \lambda / \sigma\right)\right]\right. \\
& =\sigma^{*}\left[\mathrm{f}(.) /\{1-\mathrm{F}(.)\}-\left(\varepsilon_{\mathrm{i}} / \sigma\right)\right]
\end{aligned}
$$

Where, $f($.$) and F($.$) are the standard normal$ density function and standard normal cumulative distribution function estimated at $e_{i} \lambda / s$.

The parameters of the stochastic frontier production model were estimated using maximum likelihood estimates (MLE). This way, the farm specific technical efficiency was estimated by the conditional mean of $\exp \left(-u_{i}\right)$ given the distribution of the composite error term, $\varepsilon_{\mathrm{i}}$.

The other parameters estimated included:

$$
\begin{aligned}
& \sigma^{*}=\sigma_{\mathrm{u}}^{2} \cdot \sigma_{\mathrm{v}}^{2} / \sigma^{2} \\
& =\sigma_{\mathrm{u}} / \sigma_{\mathrm{v}} \\
& =\sqrt{ }\left(\sigma_{\mathrm{u}}^{2} / \sigma_{\mathrm{v}}^{2}\right) \\
& \varepsilon_{\mathrm{i}}=\operatorname{In} \mathrm{Y}_{\mathrm{i}}-\left[\operatorname{In} \beta_{0}+\Sigma \beta_{1} \operatorname{In} \mathrm{X}_{\mathrm{i}}\right]
\end{aligned}
$$

Total variance was given by:

$$
\begin{aligned}
& \mathrm{V}(\varepsilon)=\mathrm{V}(\mathrm{u})+\mathrm{V}(\mathrm{v}) \\
& \mathrm{V}(\varepsilon)=\{(\Pi-2) / \Pi\} \sigma_{\mathrm{u}}+\sigma_{\mathrm{v}}^{2}
\end{aligned}
$$

Where, $\mathrm{V}(\mathrm{u})=\{(\Pi-2) / \Pi\} \sigma_{\mathrm{u}}^{2}$

The standard normal density function of the above equation (9) is expressed as:

$$
\begin{aligned}
& \mathrm{F}\left(\mathrm{u} / \varepsilon_{\mathrm{i}}\right)=\{1 /(1-\mathrm{F})\}\left(1 / \sqrt{ } 2 \Pi \sigma^{*}\right) \exp [-(1 / 2 \\
& \left.\sigma \lambda 2)\left(\mathrm{u}_{\mathrm{j}}+\sigma_{\mathrm{ij}} 2 \varepsilon / \sigma^{2}\right)^{2}\right]
\end{aligned}
$$

Apart from the ' $\beta$ ' coefficient estimates of the stochastic frontier model, the variance paramteres viz. $\sigma^{2}, \gamma$ and $\lambda$ were also obtained by using Maximum Likelihood Estimates (MLE) in the following manner:

$$
\sigma^{2}=\sigma_{u}^{2} / \sigma_{v}^{2}
$$

The parameter $\sigma^{2}$ (sigma-squared) is the ratio of variance of farm-specific performance of technical efficiency to the total variance of productivity of sample farmers. This is a measure of good fit and correctness of the distribution form assumed for the composite error term.

The deviation of the actual output to the best output, as explained by technical inefficiency, is given by the $\gamma$ (gamma) parameter. It refers to the systematic influences of the unexplained variables 
over the random error which go uncaptured by the production function.

The variance ratio, $\gamma$ is expressed as,

$$
\gamma=\sigma_{\mathrm{u}}^{2} / \sigma^{2}
$$

Where, $\sigma^{2}=\sigma_{u}{ }^{2} / \sigma_{v}^{2}$

On the contrary, the $\lambda$ (lamda) variance parameteris employed to confirm whether the output variations due to technical inefficieny are higher than that of random error component.

$$
\lambda=\sigma_{\mathrm{u}} / \sigma_{\mathrm{v}}
$$

The value of $\lambda$ is always assumed to be $>0$.

It is to be noted that the significance of $\sigma^{2}, \gamma$ and $\lambda$ parameters would indicate significant variations in the output levels. If the coefficients of these variance ratios are not significant then the MLE estimates would not have been sufficient to explain the variations in output as the component of technical efficiency would have been negligible (Varsani et al. 2016). If the parameter $\lambda$ attains the value of more than one, then it would indicate that the output variations due to farm level inefficiency are larger than that of the random factors that are outside the farmer's control (including observational / measurement errors and natural calamities alike). On the other hand, a zero value of $\gamma$ would indicate that the deviations from the frontier are due to noise, whereas a value of one would indicate that all the deviations are purely due to the differences in technical efficiency across the farms.

\section{Model specification}

The stochastic frontier production function employed in the present study is specified as follows:

$$
\begin{aligned}
\ln \mathrm{Y}_{\mathrm{i}} & =\beta_{0}+\beta_{1} \ln \mathrm{X}_{1}+\beta_{2} \ln \mathrm{X}_{2}+\beta_{3} \ln \mathrm{X}_{3}+\beta_{4} \ln \mathrm{X}_{4}+\beta_{5} \ln \mathrm{X}_{5} \\
& +\beta_{6} \ln \mathrm{X}_{6}+\beta_{7} \ln \mathrm{X}_{7}\left(\mathrm{v}_{\mathrm{i}}-\mathrm{u}_{\mathrm{i}}\right)
\end{aligned}
$$

Where, the subscript ' $i$ ', denotes the $i^{\text {th }}$ farmer in the sample; ' $l n$ ' is the natural logarithm (i.e. to base e); ' $Y_{i}^{\prime}$ is the actual yield of main product of relay or sole crops $(\mathrm{q} / \mathrm{ha}) ;{ }^{\prime}{ }^{\prime} \ldots . \beta_{7}$ ' are the parameters to be estimated; ' $X$ ' is the quantity of seeds used $(\mathrm{kg} /$ ha); ' $X_{2}^{\prime}$ is the hired labour (man-days/ha); ' $X_{3}^{\prime}$ is the quantity fertilizer used $(\mathrm{kg} / \mathrm{ha})$; ' $X_{4}^{\prime}$ ' is the quantity of manures used $(\mathrm{kg} / \mathrm{ha}) ;{ }^{\prime} X_{5}{ }^{\prime}$ is the machine power used (hrs/ha); ' $X_{6}{ }^{\prime}$ is the irrigation cost (Rs/ha); ' $X_{7}{ }^{\prime}$ is the pesticide cost (₹/ha); ' $\mathrm{v}_{\mathrm{i}}^{\prime}$ is the symmetric (twosided) error component; and ' $u_{i}$ ' is the one-sided error component (technical inefficiency). The model was estimated by stochastic production function and the Maximum Likelihood Estimates (MLE) of the function were obtained using the computer software programme Frontier 4.1 (Coelli and Battese, 1996).

\section{Potential yield}

Potential yields refers to the realizable yield levels that farmers could obtain by maximum utilization of resources (i.e. technical efficiency). Accordingly, the potential yield of farmers in the study area were derived by using the following specification,

$$
\begin{aligned}
& \mathrm{YG}=(\mathrm{FY}-\mathrm{AY}) \times 100 / \mathrm{TE} \\
& \mathrm{PY}=\mathrm{YG}+\mathrm{AY}
\end{aligned}
$$

Where: ' $Y G$ ' is the existing yield gap; ' $F Y$ ' is the frontier yield attained by the farmers; ' $P Y^{\prime}$ is the potential yield that is attainable; 'AY' is the actual (realized) yield of the farmers; and 'TE' is the technical efficiency (\%) of the farmers in the study area.

\section{Determinants of technical efficiency}

In order to find out the key determinants of technical efficiency, a simple linear multiple regression equation of the form given in equation (14) was estimated using Ordinary Least Squares (OLS) technique (Kalirajan, 1990; Bravo-Ureta and Evenson, 1994; Parikh and Shah, 1994; Shanmugam, 2003; Bhende and Kalirajan, 2007; and Varsani et al., 2016).

$$
\mathrm{TE}_{\mathrm{i}}=\underset{\mathrm{b}_{7} \mathrm{X}_{7}+\mathrm{e}_{\mathrm{i}}}{\mathrm{b}_{1}}+\mathrm{b}_{1} \mathrm{X}_{1}+\mathrm{b}_{2} \mathrm{X}_{2}+\mathrm{b}_{3} \mathrm{X}_{3}+\mathrm{b}_{4} \mathrm{X}_{4}+\mathrm{b}_{5} \mathrm{X}_{5}+\underset{6}{\mathrm{~b}_{6} \mathrm{X}_{6}}+
$$

Where, 'TE' is the technical efficiency (\%) of the ' $\mathrm{i}^{\text {th' }}$ farm; ' $\mathrm{X}_{1}$ ' is the acreage under relay cropping or sole crops (in ha); ' $X_{2}$ ' is the experience in relay or sole cropping system cultivation (in years); ' $X_{3}$ ' is the education level of the farmer (in years); ' $X_{4}$ ' is the family labour (in numbers); ' $X_{5}$ ' is the land Fragmentation Index (LFI $=$ No. of fragments of cropped land/ Total area under sole crops / relay crop); ' $X_{6}$ ' is the institutional support availed (dummy variable, $1=$ visit to the field by public extension agency personnel; $0=$ otherwise); and 
' $\mathrm{X}_{7}$ ' is the distance travelled by farmers to purchase inputs in the markets $(\mathrm{km}) ;{ }^{\prime} \mathrm{b}_{0}$ ' is the intercept term; ' $b_{1} \ldots b_{7}^{\prime}$ are the coefficients of respective factors influencing technical efficiency and ' $\mathrm{e}_{\mathrm{i}}$ ' is the random error term.

\section{RESULTS AND DISCUSSION}

\section{General characteristics of the sample farm households}

Before discussing the actual findings of the stochastic frontier production function analysis, the general charactistics of the sample under study needs to be furnished. This would provide a basic understanding of the nature of the influencing factors as well as the background in which the factors operate. Accordingly, the profile and input use characteristics of all the three categories of farmers have been shown in Table 1. The farm experience (years) of relay cropping farmers (32.34) was found to be higher than that of sole groundnut (27.81) and sole pigeonpea (23.67) farmers. But the education level of sole pigeonpea farmers (7.82 years) was indeed higher than the other two.

Surprisingly, the acreage of sole groundnut farmers was higher (1.85) and lower with relay cropping farmers (1.38) indicating lesser preference among farmers for crop diversification. On the other hand, land fragmentation was found to be the least among relay cropping farmers (0.72) paving way for the possibility of higher level of efficiency in the farms. In terms of input use pattern, the sole groundnut farmers were found to be using higher level of inputs since groundnut is a commercial crop and a ruling kharif crop in the study area. At the same time, the groundnut-pigeonpea relay cropping farmers were found using less amount of inputs for the relay pigeonpea crop when compared to the sole (main)

Table 1: Profile and input use characteristics of sample farm households

\begin{tabular}{cccccc}
\hline & Independent variables & Sole groundnut \\
S1. & Mean & $\begin{array}{c}\text { Sole } \\
\text { No. }\end{array}$ & $\begin{array}{c}\text { pelay } \\
(\mathrm{n}=48)\end{array}$ & $\begin{array}{c}\text { Reonpea } \\
\text { Cropping } \\
(\mathrm{n}=48)\end{array}$ & $\begin{array}{c}\text { A priori } \\
\text { (expected) sign }\end{array}$ \\
\cline { 2 - 4 } & & Mean & Mean & & \\
\hline
\end{tabular}

Statistics of stochastic frontier production model:

(Dependent variable: Actual production of the farmers $(\mathrm{kg} / \mathrm{ha})$

\begin{tabular}{lcccccc}
\hline 1 & Seed (kg/ha) & $X_{1}$ & 129.44 & 18.75 & 144.12 & + \\
2 & Hired labour (days/ha) & $X_{2}$ & 68.56 & 33.14 & 92.31 & + \\
3 & Fertilizers (kg/ha) & $X_{3}$ & 168.04 & 86.82 & 211.53 & + \\
4 & Manures (cart loads/ha) & $X_{4}$ & 14.70 & 7.92 & 13.45 & + \\
5 & Machine power (hrs/ha) & $X_{5}$ & 6.72 & 3.39 & 6.41 & + \\
6 & Irrigation cost (Rs./ha) & $X_{6}$ & 1211.46 & 584.21 & 1345.69 & + \\
7 & Pesticide cost (Rs./ha) & $X_{7}$ & 1181.66 & 792.43 & 1345.22 & + \\
\hline
\end{tabular}

Statistics of OLS regression model:

(Dependent variable: Technical efficiency of the farmers (\%)

\begin{tabular}{|c|c|c|c|c|c|c|}
\hline 8 & Acreage (in ha) & $\mathrm{D}_{1}$ & 1.85 & 1.68 & 1.38 & $+/-$ \\
\hline 9 & Experience (in years) & $\mathrm{D}_{2}$ & 27.81 & 23.67 & 32.34 & + \\
\hline 10 & Education (in years) & $\mathrm{D}_{3}$ & 5.15 & 7.82 & 4.13 & + \\
\hline 11 & Family labour (days/ha) & $\mathrm{D}_{4}$ & 24.32 & 14.68 & 37.66 & + \\
\hline 12 & Land fragmentation index & $\mathrm{D}_{5}$ & 2.16 & 1.19 & 0.72 & - \\
\hline 13 & Institutional support dummy & $\mathrm{D}_{6}$ & 0.484 & 0.562 & 0.524 & + \\
\hline 14 & Market access (in km) & $\mathrm{D}_{7}$ & 10.51 & 14.26 & 12.38 & - \\
\hline$\#$ & Main product yield (qtl/ha) & NA & 21.06 & 15.13 & $35.13^{\#}$ & NA \\
\hline \# & Gross returns (Rs./ ha) & NA & 95,620 & 77,483 & 153,033 & NA \\
\hline
\end{tabular}

Note: 1. "Equivalent yield of groundnut $=P_{R} \times Q_{R} / P_{M^{\prime}}$ Whereby: PR is the price per unit of main product of relay crop (pigeonpea); $Q R$ is the quantity of main product of relay crop and $P M$ is the per unit price of main product of main crop (groundnut);

2. NA-stands for 'not applicable'. 
pigeonpea farmers. As a matter of fact, the practice of relay cropping is also found to be beneficial in the study area since it was able to generate higher gross returns ( $₹ 153,033)$ with relatively lesser use of inputs when compared to that of the other two sole cropping systems separately. Thereby, the practice of relay cropping need to be upscaled among the farmers. All the variables were selected after careful literature analysis and pilot survey and they have been used in two different models viz. stochastic frontier production and multiple linear regression. Almost all the variables were expected to have positive effects, whereas land fragmentation index and market access were assumed to have negative effect and acreage was expected to have either positive or negative effect over technical efficiency.

\section{Estimation of Frontier Production Function}

The maximum likelihood estimates (MLE) of the stochastic production parameters for the cropping systems under study are furnished in Table 2 . Overall, the variance parameters of all the three cropping systems such as $\sigma^{2}, \gamma$ and $\lambda$ were found to be significantly different from zero ensuring that the variations in farmers's output in the study area were mostly due to technical inefficiency alone. In other words, the one sided error component ' $u_{i}$ ' dominated the systematic error ' $v_{i}$ ' and the productivity shortfall from the frontier were within the farmer's control. Particularly, the variance parameter lambda $(\lambda)$ was found to be greater than one among all the categories of farmers such as sole groundnut farmers (1.104), sole pigeonpea farmers (1.923) and relay cropping farmers (2.263) indicating a good fit for the model (Tadesse and Krishnamoorthy, 1997).

Similarly, the sigma-squared $\left(\sigma^{2}\right)$ variance ratio values were found to be significantly different from zero in all the three cropping systems implying the correctness of the distributional from assumed for the composite error term. The gamma $(\gamma)$ values were found to be significantly different from zero and it was the highest among relay cropping farmers (0.838) followed by sole pigeonpea farmers (0.787) and sole groundnut farmers (0.549). The gamma estimates indicated that the contribution of random factors to the variation in farmers' output was limited in all the three cropping systems. Thereby, the existing technical inefficiencies can be controlled with optimal usage and allocation of farm resources. As a matter of fact, the contribution of random error component to the variation in farm output was very less for relay cropping farmers $(16.20 \%)$ indicating that the sustainability of the relay cropping can also be improved with reallocation of the resources alone. The significance of the gamma values also

Table 2: Cropping system-wise maximum likelihood estimates (MLE) of stochastic frontier production function

\begin{tabular}{ccccccc}
\hline Farm input & \multicolumn{2}{c}{$\begin{array}{c}\text { Sole groundnut } \\
(\mathbf{n}=\mathbf{4 8})\end{array}$} & \multicolumn{2}{c}{$\begin{array}{c}\text { Sole pigeonpea } \\
(\mathbf{n}=48)\end{array}$} & \multicolumn{2}{c}{$\begin{array}{c}\text { Relay cropping } \\
(\mathbf{n}=\mathbf{4 8})\end{array}$} \\
\cline { 2 - 7 } & Coeffi. & SE & Coeffi. & SE & Coeffi. & SE \\
\hline Constant & 1.097 & 3.557 & $2.949^{* * *}$ & 1.098 & 2.790 & 4.667 \\
Seed, $X_{1}$ & 0.754 & 0.525 & 0.237 & 0.244 & 0.106 & 0.396 \\
Human labour, $X_{2}$ & 0.423 & 0.471 & -0.047 & 0.275 & $1.104^{*}$ & 0.567 \\
Fertilizer, $X_{3}$ & -0.029 & 0.044 & -0.019 & 0.806 & $0.276^{* * *}$ & 0.105 \\
Manure, $X_{4}$ & 0.003 & 0.013 & 0.001 & 0.006 & 0.003 & 0.004 \\
Pesticide cost, $X_{5}$ & -0.035 & 0.036 & 0.004 & 0.090 & $-0.266^{* *}$ & 0.107 \\
Machine power, $X_{6}$ & $0.043^{* *}$ & 0.021 & 0.003 & 0.044 & $0.101^{* *}$ & 0.048 \\
Irrigation cost, $X_{7}$ & -0.037 & 0.023 & $0.179^{*}$ & 0.095 & 0.014 & 0.015 \\
Sigma-squared $\left(\sigma^{2}\right)$ & $0.302^{* * *}$ & 0.114 & $0.039^{* * *}$ & 0.017 & $0.028^{* * *}$ & 0.009 \\
Gamma $(\gamma)$ & $0.549^{* *}$ & 0.283 & $0.787^{* * *}$ & 0.233 & $0.838^{* * *}$ & 0.156 \\
Lambda $(\lambda)$ & $1.104^{* * *}$ & 0.237 & $1.933^{* * *}$ & 0.095 & $2.263^{* * *}$ & 0.058 \\
Log likelihood & \multicolumn{2}{c}{-28.92} & \multicolumn{2}{c}{27.12} & & 37.40 \\
\hline
\end{tabular}

Note: $1 .{ }^{*},{ }^{* *}$ and ${ }^{* * *}$ denotes significance at 10, 5 and 1 per cent levels, respectively.

2. Coeffi. Refera to $\beta$ coefficients and SE is the standard errors of the factors in question. 
indicated OLS estimates alone will not be sufficient to explain the inefficiencies, thereby the use of stochastic production function is justified.

Further, the maximum likelihood estimates of stochastic production function have shown that the coefficient of machine power (0.043) was positively significant for sole groundnut farmers and irrigation cost (0.179) was positively significant in the case of sole pigeonpea farmers. These significant coefficients denote the variation or possible change in aggregate output of sole crops in the study area as a result of a unit change in inputs under the farmer's control. Rao et al. (2003) also reported similar results regarding the technical efficiency in production of three major crops viz., rice, groundnut and cotton in Andhra Pradesh. In groundnut + pigeonpea relay cropping, the ' $\beta$ ' estimates of stochastic production function showed that the estimated value of the coefficient of pesticide cost $(-0.266)$ was negative and significant indicating over use of the inputs. At the same time, the coefficients of human labour (1.104), fertilizer (0.276) and machine power (0.101) were positively significant indicating their positive role in relay cropping production. The production elasticities reveal that among the farmers practicing relay cropping in the study area, an increase in $1 \%$ of human labour, fertilizer and machine power would result in the increase of output to the tune of $1.1,0.27$ and 0.10 per cent, respectively.

\section{Distribution of technical efficiency}

Typical of the Cobb - Douglas production function, the estimated coefficients for the specified function can be explained as the elasticity of the explanatory variables. As it could seen from Table 3, the mean technical efficiency (TE) was found to be the highest for relay cropping farmers $(89.04 \%)$, followed by sole pigeonpea farmers $(87.18 \%$ ) and sole groundnut farmers $(74.52 \%)$. The technical efficiency of relay cropping farmers revealed that the farmers were not fully efficient as the observed output was 11 per cent less than the frontier (maximum) output, whereas in the case of sole groundnut farmers the observed output was found to be 25.50 per cent less than the maximum output and the same for sole pigeonpea farmers was 13 per cent less than the maximum output in the study area.

The findings of Table 3 further show that in case of sole groundnut farmers, 13 out of 48 farms have technical efficiency level below 70 per cent, 35 farms between 71 to 90 per cent, while no farms showed technical efficiency exceeding 90 per cent. Varsani et al. (2016) also reported similar findings regarding groundnut production in Saurashtra region of Gujarat state. In case of sole pigeonpea, all the farmers in the study area were found to have above 65 per cent technical efficiency. Moreover, 18 out of 48 sole pigeonpea farmers have technical efficiency levels between 91 and 95 per cent whereas 29 farmers out of 48 were in the range between 71 and 90 per cent. With regards to relay cropping, only 9 out of 48 farmers have technical efficiency level below 85 per cent, 33 farmers between 86 and 95 per cent and 6 farmers showed technical efficiency of more than 95 per cent.

At the same time, the efficiency differential between the technically most-efficient relay cropping farmer and the technically least-efficient relay cropping

Table 3: Distribution of sample farmers on the basis of their technical efficiency

\begin{tabular}{ccccccc}
\hline \multirow{2}{*}{$\begin{array}{c}\text { Technical efficiency } \\
(\%)\end{array}$} & \multicolumn{2}{c}{ Sole groundnut $(\mathbf{n}=\mathbf{4 8})$} & \multicolumn{2}{c}{ Sole pigeonpea $(\mathbf{n}=\mathbf{4 8})$} & \multicolumn{2}{c}{ Relay cropping $(\mathbf{n}=\mathbf{4 8})$} \\
\cline { 2 - 7 } & No. of farms & \% to total & No. of farms & \% to total & No. of farms & \% to total \\
\hline $35-60$ & 3 & 6.25 & - & - & - & - \\
$61-65$ & 5 & 10.42 & - & - & - & - \\
$66-70$ & 5 & 10.42 & 2 & 4.17 & 1 & 2.08 \\
$71-75$ & 15 & 31.25 & 1 & 2.08 & 2 & 4.16 \\
$76-80$ & 11 & 22.92 & 1 & 2.08 & 2 & 4.16 \\
$81-85$ & 6 & 12.50 & 13 & 27.09 & 4 & 8.33 \\
$86-90$ & 3 & 6.25 & 12 & 25.00 & 15 & 31.27 \\
$91-95$ & - & - & 18 & 37.50 & 18 & 37.50 \\
$>95$ & - & - & 1 & 2.08 & 6 & 12.50 \\
Total farms & 48 & 100.00 & 48 & 100.00 & 48 & 100.00 \\
Mean efficiency (\%) & \multicolumn{7}{r}{} \\
\hline
\end{tabular}


farmer was found to be 30.22 per cent indicating a wide efficiency gap. The mean technical efficiency level of groundnut-pigeonpea relay cropping farmers was estimated to be 89.04 per cent with a minimum efficiency of 66.06 per cent and a maximum efficiency of 96.28 per cent. This implies that on an average, the farmers were able to obtain 89 per cent of potential output from a given combination of production inputs. The implication of the result is such that an average farmer is found to be requiring 7.47 per cent reduction in the use of inputs i.e. $\{(1-0.891 / 0.963) \times 100\}$ to attain the status of the most efficient farmer while the least performing farmer would need 31.36 per cent reduction i.e. $\{(1-0.661 / 0.963) \times 100\}$ in input usage to become the most efficient farmer. These results refurbish the findings of Maurice et al. (2012) in the groundnut-pigeonpea relay cropping in Nigeria State of Africa who revealed the mean technical efficiency of realy cropping system at 88 per cent with the efficiency range between 66.94 per cent and 95.78 per cent.

\section{Potential yield}

Yield gaps always tend to exist as the farmers do dither away from achieving highest levels of technical efficiency either due to the bottlenecks in technological adoption or by the inconvenient natural factors. As it could be seen from Table 4, the potential yields of farmers in the study area are furnished against all the levels of technical efficiency. In case of sole groundnut cropping system, the actual yield levels can be improved up to $1.16 \mathrm{qtl} / \mathrm{ha}$ among the farmers existing in the lowest technical efficiency range between 35 and 50 per cent. On an average, an increased yield of at least $1 \mathrm{qtl} /$ ha can be achieved in the study area among sole groundnut farmers in the short-run with improved levels of technical efficiency. For pigeonpea farmers existing in the lowest technical range between 66 and 70 per cent, a yield increase of $3.46 \mathrm{qtl} / \mathrm{ha}$ is required to achieve the frontier yield. On an average, at least $1.67 \mathrm{qtl} /$ ha additional yield per pigeonpea farmer can be achieved in the study area with maximum utilization of inputs. The frontier yield (equivalent) of groundnut-pigeonpea relay cropping farmers was found to be $37.02 \mathrm{qtl} /$ ha. On an average, the yield to be bridged was only $0.89 \mathrm{qtl} / \mathrm{ha}$ under relay cropping which was much lesser than the other two cropping systems. In fact, for the relay cropping farmers existing in the highest technical efficiency range a yield increase of $0.18 \mathrm{qtl} / \mathrm{ha}$ alone is required to achieve the potential yield, whereas the requirement for the same was slightly higher for sole groundnut farmers (0.22 qtl/ha) and highest for sole pigeonpea farmers ( $0.36 \mathrm{qtl} / \mathrm{ha})$. The findings emphasize that the relay cropping system can ensure not only higher levels of technical efficiency but also higher productivity levels, thereby, fulfilling the basic requisites of sustainability.

\section{Determinants of technical efficiency}

Though the same production technology or a technical practice is available in a study area, the access to it by the farming community may be

Table 4: Distribution of sample farmers on the basis of technical efficiency (Yield in qtl / ha)

\begin{tabular}{|c|c|c|c|c|c|c|c|c|c|}
\hline \multirow{2}{*}{ TE (\%) } & \multicolumn{3}{|c|}{ Sole groundnut $(n=48)$} & \multicolumn{3}{|c|}{ Sole pigeonpea $(n=48)$} & \multicolumn{3}{|c|}{ Relay cropping ( $\mathrm{n}=48$ ) } \\
\hline & AY & ATE & PY & AY & ATE & PY & AY & ATE & PY \\
\hline $35-60$ & 20.29 & 50.87 & 21.45 & - & - & & - & - & \\
\hline $61-65$ & 20.33 & 62.37 & 21.73 & - & - & & - & - & \\
\hline $66-70$ & 20.46 & 67.48 & 21.89 & 12.72 & 67.16 & 16.18 & 32.23 & 68.00 & 35.49 \\
\hline $71-75$ & 20.89 & 71.24 & 22.09 & 13.61 & 72.38 & 16.69 & 33.65 & 71.88 & 36.07 \\
\hline $76-80$ & 21.16 & 76.45 & 22.25 & 13.74 & 78.23 & 16.97 & 34.40 & 78.84 & 36.47 \\
\hline $81-85$ & 21.23 & 82.62 & 22.35 & 15.04 & 82.93 & 17.39 & 35.72 & 84.00 & 36.81 \\
\hline $86-90$ & 22.36 & 86.41 & 22.58 & 16.35 & 87.88 & 17.69 & 36.32 & 87.92 & 36.94 \\
\hline $91-95$ & - & - & - & 16.96 & 92.84 & 17.80 & 36.76 & 92.88 & 37.00 \\
\hline$>95$ & - & - & - & 17.50 & 95.95 & 17.86 & 36.83 & 96.34 & 37.01 \\
\hline \multirow[t]{2}{*}{ Mean } & 21.24 & 74.52 & 22.24 & 15.95 & 87.18 & 17.62 & 36.02 & 89.04 & 36.91 \\
\hline & & $F Y=22.58$ & & & $\mathrm{FY}=17.87$ & & & $\mathrm{FY}=37.0$ & \\
\hline
\end{tabular}

Note: AY - Actual Yield; PY - Potential Yield; FY = Frontier Yield; and ATE - Average Technical Efficiency. 
Table 5: Factors influencing technical efficiency in the study area

\begin{tabular}{cccc}
\hline Variable & $\begin{array}{c}\text { Coefficients of sole } \\
\text { groundnut }\end{array}$ & $\begin{array}{c}\text { Coefficients of } \\
\text { sole pigeonpea }\end{array}$ & $\begin{array}{c}\text { Coefficients of relay } \\
\text { cropping }\end{array}$ \\
\hline Intercept & $90.85^{* * *}(20.06)$ & $99.83^{* * *}(7.66)$ & $82.20^{* * *}(7.20)$ \\
Acreage (ha), $\mathrm{D}_{1}$ & $-3.13(2.59)$ & $-1.18(1.81)$ & $-1.19(1.36)$ \\
Experience (years), $\mathrm{D}_{2}$ & $0.56^{* *}(0.24)$ & $0.24^{* *}(0.11)$ & $0.37^{* *}(0.18)$ \\
Education (years), $\mathrm{D}_{3}$ & $0.08^{*}(0.04)$ & $0.33^{*}(0.17)$ & $0.10^{* * *}(0.04)$ \\
Family labour (nos.), $\mathrm{D}_{4}$ & $0.43(0.81)$ & $0.71(0.51)$ & $0.41(0.71)$ \\
Land Fragmentation Index (LFI), $\mathrm{D}_{5}$ & $-0.53(5.23)$ & $-5.94^{* *}(2.71)$ & $-3.49^{* *}(1.63)$ \\
Institutioanl support (dummy), $\mathrm{D}_{6}$ & $0.73^{* *}(0.37)$ & $0.26^{* * *}(0.10)$ & $0.12^{* * *}(0.01)$ \\
Market access (km), $\mathrm{D}_{7}$ & $-0.32^{*}(0.19)$ & $-0.09(0.11)$ & $-0.08^{* * *}(0.02)$ \\
$\mathrm{R}^{2}$ & 0.52 & 0.55 & 0.48 \\
\hline
\end{tabular}

Note: $1 .{ }^{*},{ }^{* *}$ and ${ }^{* * *}$ denotes significance at 10,5 and 1 per cent levels, resp.

2. Figures inside the parantheses are standard errors.

different. Even when the access is more or less levelled with the help of institutional support, the technological adaptation among the farmers may again be different. That is why, only a few farmers are able to achieve higher level of technical efficiencies while many others fail to comply. henceforth, it is pertinent to identify the factors influencing farmspecific technical efficiency. Accordingly, a multiple linear regression analysis (OLS) was attempted on the level of technical efficiency (\%) of farmers using a number of influencing factors existing in the study area and the findings are furnished in Table 5.

\section{Acreage (ha)}

Despite being non-significant the average effect of farm size variable was found to be negative over technical efficiency in all the three cropping systems. Earlier, the literature revealed contradictory findings about the influence of the farm size or acreage variable. For instance, Bhende and Kalirajan (2007) argue that the influence of acreage variable over technical efficiency would be negative as with the increase in farm size it would be difficult to complete critical farm operations on time. At the same time, Maurice et al. (2012) opine positive effect of acreage on technical efficiency as the feasibility of crop specialization in large farms can readily increase technical efficiency among farmers. But the difficulty of the large farmers in the study area to avail and apply inputs on time as well as the existing field constraints in finding and deploying farm labourers on time might be the reason for the influence of farm size to be negative.

\section{Experience in farming (years)}

The coefficients of experience was positively significant for sole groundnut (0.56), sole pigeonpea $(0.24)$ as well as relay cropping (0.37) farmers indicating that technical efficiency is bound to increase with the farmers gaining experience in a particular cropping system. Particularly, on an average, for every one year increase in the experience of relay cropping farmers the technical efficiency was found to have increased by 0.37 per cent. Such a positive relationship would have been possible since with the increase in experience the managerial capacity of the farmers would also increase leading to informed decisions regarding the use of resources. The present findings are in line with that of Maurice et al. (2012) and Varsani et al. (2016) who also reported the significant and positive effect of experience over average technical efficiency. It is to be noted that the age factor was dropped from the initial model since it was found to have multicollinearity issue with experience.

\section{Education (years)}

In line with the a priori assumption, the effect of education factor was found to be both positive and significant in all the three cropping systems under study. The effect was more over the technical efficiency of sole pigeonpea cultivators (0.24) followed by relay cropping farmers (0.10) and sole groundnut (0.08) growers. So, with every one year increase in education among relay cropping farmers the technical efficiency was found to increase 0.10 $\%$, ceteris paribus. This effect need not be of formal 
education alone (i.e. schooling and collegiate), but also may include exposure given to the farmers by the public institutions through various trainings and capacity building programmes.

\section{Family labour (numbers)}

The coefficient estimates of the family labour variable were found to be positive but non-significant in all the cropping systems. In case of labour intensive cropping systems like that of relay cropping, the farmers would be in an advantageous position if the family labourers are readily available. Besides, the family labourers would be useful in managing the hired labourers and for on-time execution of farm decisions.

\section{Land fragmentation index (ratio)}

In order to find out the extent of implications of land fragmentation upon technical efficiency, a fragmentation index was developed by dividing the total numbers of plots (fragments) of cropped land by the total acreage under the study crops. The coefficient of land fragmentation was negative but not significant in case of sole groundnut $(-0.53)$ and the same was negatively significant for sole pigeonpea (-5.94) and relay cropping (-3.94) farmers. In other words, for every 1 unit increase in land fragmentation index, the efficiency of relay cropping farmers got decreased by 3.49 per cent. Land fragmentations were observed to be higher in large farm-size groups in the study area as they tend to have many field plots and sub-plots. In such a case, it becomes difficult to perform farm operations timely and uniformly. For instance, under fragmented conditions, it cannot be expected from farmers to carry out intercultural operations at the same time in all their plots and it may also be difficult to operate tractors and other farm machineries. Thereby, the managerial ability of the farmers may not be effective. As a result, technical efficiency of the farmers may decrease with every increase in land fragmentations.

\section{Institutional support (dummy)}

The institutional support was found to be a highly significant determinant of technical efficiency and its average effect was highest among sole groundnut farmers (0.73) followed by sole pigeonpea (0.26) and relay cropping $(0.12)$ farmers. Visit of extension personnel to the farmer's field was considered as a proxy for institutional support. The contact of farmers with the extension / institutional agents may increase farmer's exposure or improve farmer's knowledge about a particular production technology. The extension agents may also enable farmers to have access to training programmes and capacity building programmes which in turn might have further improved technical efficiency in the study area. For every 1 per cent increase in the probability of the farmer meeting up with the extension / institutional agent, the odds of technical efficiency increased by 0.12 per cent among relay cropping farmers.

\section{Input market access (km)}

As expected (a priori), the beta coefficients of input market access was found to be negative in all the three cropping systems. Besides, the variable was both negative and significant at 5 per cent level in case of sole groundnut farmers (-0.32) and relay cropping farmers (-0.08). On an average, for every $1 \mathrm{~km}$ increase in the distance travelled by the relay cropping farmers to purchase farm inputs from the markets the technical efficiency was found to decrease by 0.08 per cent. As market proximity may lead to better access and use of farm inputs on real-time basis, the same would have led to the increases in technical efficiency.

\section{CONCLUSION}

Estimation of location-specific technical efficiency is important to not only increase crop productivity levels in a region but also to maintain farm sustainability. Farmers will also be motivated to experiment sustainable agricultural practices only when it is rewarding. The analysis of technical efficiency of the present study has revealed that, on an average, the technical efficiency of groundnutpigepea relay cropping farmers (89\%) was more than that of sole cropping farmers. Further, there is also scope for increasing technical efficiency of realy cropping farmers by 11 per cent in the shortrun through efficient utilization of existing inputs given the current state of technology. The maximum likihood estimates of stochastic frontier production function have indicated positive and significant effect of human labour, machine power and fertilizer on the production of relay cropping farmers. At the 
same time, plant protection cost revealed negatively significant effect on the average farm production indicating over use of this factor among the relay cropping farmers. Besides, the findings also revealed experience, education and institutional support as key determinants of technical efficiency. Since reallocation and optimal utilization of resources alone can improve both technical efficiency and farm sustainability, institutional efforts should be on the anvil to couple real-time extension mechanism with timely access and availability of farm inputs.

\section{REFERENCES}

Aigner, D.J., Lovell, C.A. and Schmidt, P.V. 1977. Formulation and estimation of stochastic frontier production function models. Journal of Econometrics, 6(1): 21-37.

Bathon, A.H. and Maurice, D.C. 2015. Analysis of technical efficiency of groundnut-based cropping systems among farmers in Hong Local Government Area of Adamawa State, Nigeria. Journal of Agricultural Economics. Environment and Social Sciences, 1(1): 61-69.

Bhende, M.J. and Kalirajan, K.P. 2007. Technical efficiency of major food and cash crops in Karnataka (India). Indian Journal of Agricultural Economics, 62(2): 178-191.

Bravo-Ureta, B.E. and Evenson, R.E. 1994. Efficiency in agricultural production: the case of peasant farmers in Eastern Paraguay. Agricultural Economics, 10(1): 27-37.

Coelli, T. and Battese, G. 1996. Identification of factors which influence the technical inefficiency of India farmers. Australian Journal of Agricultural Economics, 40(2): 103-128.

Datta, K.K. and Joshi, P.K. 1992. Economic efficiencies and land augmentation to increase agricultural production: A comparative analysis of investment priorities. Indian Journal of Agricultural Economics, 47(3): 468-476.

Deshpande, R. and Bhende, G. 2003. Analyze the efficiency of agriculture production and examine the technological gap. International Journals of Innovative Research $\mathcal{E}$ Studies, 16 (6): 231-235.

Jayaram, G.H., Chandrashekar, G.S. and Lalith, S.A. 1992. An economic analysis of technical efficiency in pigeonpea cultivation in Mandya: Some issues in resource pricing. Indian Journal of Agricultural Economics, 47(4): 677-682.

Jondrow, J., Lovell, C., Materov, S. and Schmidt, P. 1982. On the estimation of technical use efficiency in the stochastic frontier production function model. Journal of Econometrics, 19(4): 233-238.
Kalirajan, K.P. and Shand, R.B. 1989. On measuring the contribution of human capital to agricultural production. Indian Economic Review, 24(8): 247-261.

Kalirajan, K.P. 1990. On measuring economic efficiency. Journal of Applied Econometrics, 5(1): 75 - 85.

Maurice, S.K., Edriss, J A. and Nair, B.G. 2012. Measurement of technical efficiency of pigeonpea growers in Nigeria State of Africa: A data envelopment analysis approach. Agricultural Science Digest, 32(2):105-110.

Parikh, A. and Shah, K. (1994). Measurement of technical efficiency in the North-West frontier provinces of Pakistan. Journal of Agricultural Economics, 45(10): 132-138.

Rao, C.A., Chowdary, K.R., Reddy, Y.V. and Krishna, G.V. 2003. Measuring and explaining technical efficiency in crop production in Andhra Pradesh. Indian Journal of Agriculture Economics, 58(4): 768-780.

Sharma, V. and Datta, K. 1997. Technical efficiency in wheat production on reclaimed alkali soils productivity. Agricultural Economics Research Review, 38(2):334.

Shanmugam, K.R. 2003.Technical efficiency of rice, groundnut and cotton farms in Tamil Nadu. Indian Journal of Agricultural Economics, 58(1): 101-114.

Shanmugam, K.R. and Venkataramani, A. 2017. Technical efficiency in agricultural production and its determinants: An exploratory study at the district level. Indian Journal of Agricultural Economics, 61(2): 169-184.

Tadesse, B. and Krishnamoorthy, S. 1997. Technical efficiency of paddy farmers of Tamil Nadu: An Analysis based on farm and ecological zone. Journal of Agricultural Economics, 16(1): 185-192.

Taru, V. B., Lawal, H. and Tizhe, I. 2011. Technical efficiency of sole cowpea production in Adamawa State, Nigeria: A Cobb-Douglas stochastic frontier function. Journal of Economics and International Finance, 3(8): 504-507.

Varsani, J.V., Shiyani, R.L., Ardeshna, N.J. and Swaminathan, B. 2016. Technical efficiency analysis of groundnut production in Saurashtra region of Gujarat. International Journal of Agriculture Sciences, 8(54): 852 -858.

Wakili, A.M. 2012. Technical efficiency of sorghum production in Local Government Area of Adamawa State, Nigeria. Russian Journal of Agricultural and Socio-Economic Sciences, 1(2): 10-15. 
